\title{
Childhood deaths from intussusception in England and Wales, 1984-9
}

\author{
Mark D Stringer, Gordon Pledger, David P Drake
}

\begin{abstract}
Objective-To assess the incidence of potentially avoidable factors contributing to death of children with intussusception.

Design-Review of children who died with intussusception in England and Wales between 1984 and 1989 from data of the Office of Population Censuses and Surveys, case notes, coroners' records, and necropsy reports.

Main outcome measures-Unambiguous objective criteria such as failure to diagnose intussusception within 24 hours of admission.

Results - 33 children died of acute intussusception in England and Wales between 1984 and 1989 compared with 67 in the previous six years. Their median age was 7 months (range 2 months to 12 years), and two thirds were boys. Half of the deaths occurred at home or soon after arrival at hospital but 15 patients had surgery. Potentially avoidable factors contributing to death were identified in $20(61 \%)$ children, all but three of whom had ileocolic intussusception. These factors were excessive delay in diagnosis, inadequate intravenous fluid and antibiotic therapy, delay in recognising recurrent or residual intussusception after hydrostatic reduction, and surgical complications. Of the 13 patients in whom no avoidable factors were identified, there were nine of 11 children with isolated small bowel intussusception, who tended to have atypical presentations.

Conclusion-Although the mortality from intussusception has declined, there remains ample opportunity for improved management.
\end{abstract}

\section{Introduction}

Intussusception is the commonest cause of intestinal obstruction in young children, two thirds of cases occurring in infancy. The condition typically affects previously healthy subjects and once diagnosed is readily treated by non-operative methods of reduction or surgery.' In England and Wales acute intussusception has an incidence of $1-2 / 1000$ live births ${ }^{2}$ and accounts for around 700 hospital admissions each year. ${ }^{3.5}$ The number of deaths each year in England and Wales has fallen gradually from around 30 in the $1960 \mathrm{~s}$ to under 10 in the early 1980s. ${ }^{6}$ This study of children who died with a diagnosis of intussusception between 1984 and 1989 was undertaken in order to identify potentially avoidable factors still contributing to death. Subjects and methods

We obtained from the Office of Population Censuses and Surveys a copy of the death certificates of all 33 children aged under 15 in England and Wales whose death between 1984 and 1989 had been certified as due

\author{
Authority, Newcastle upon \\ Tyne \\ Gordon Pledger, MD, director \\ of public health \\ Correspondence to: \\ Mr M D Stringer, \\ Department of Paediatric \\ Surgery, Institute of Child \\ Health, London \\ WC1N 1EH. \\ Hospitals for Sick
Children, London \\ senior registrar in paediatric \\ David P Drake, FRCS
}

BMJ VOLUME 304
Case notes, necropsy reports, and coroners' statements were obtained from hospital consultants, general practitioners, and local coroners. Considering the difficulties of accurately extracting data in a retrospective study of case histories, we decided to apply unambiguous objective criteria (such as failure to diagnose intussusception within 24 hours of admission to hospital) when assessing case material for avoidable factors contributing to death. Such criteria have been employed by others in similar studies. ${ }^{78}$

\section{Results}

SOURCES OF INFORMATION

Coroners' reports were obtained for the five deaths occurring at home and were supplemented by information from inquests and, in two cases, details from general practitioners. Of the 28 hospital deaths, the case notes of 22 children and a detailed summary of one other were available. Coroners' reports were available for the remaining five hospital deaths, all of which occurred on arrival at accident and emergency departments. A coroner's report was received for all 27 patients in whom necropsy was performed.

\section{CLINICAL FEATURES}

All 33 children had intussusception documented either at operation or at necropsy.

Age and sex distribution-There were 23 boys and 10 girls with a median age of 7 months (range 2 months to 12 years) (table I). Although most deaths were in children aged under 2 years, five occurred in children over 8 .

TABLE I -Age distribution of children who died of intussusception

\begin{tabular}{|c|c|c|c|c|c|c|c|c|c|}
\hline & \multicolumn{9}{|c|}{ Age } \\
\hline & \multicolumn{5}{|c|}{ Months } & \multicolumn{3}{|c|}{ Years } & \multirow[b]{2}{*}{ Total } \\
\hline & $\leq 3$ & -6 & -9 & -12 & -24 & $2-5$ & -10 & -15 & \\
\hline No of deaths & 6 & 7 & 10 & 1 & 3 & 1 & 3 & 2 & 33 \\
\hline
\end{tabular}

Pathology-Of the 33 intussusceptions, 18 were complicated by intestinal infarction. In 21 patients the intussusception was of the ileocolic variety, in nine ileoileal, in two jejunojejunal, and one child had a caecocolic intussusception. Pathological lead points were recorded in only two: an 8 year old boy with an infarcted small bowel polyp, and a Meckel's diverticulum in a 7 month old boy.

Time and place of death-Half of the deaths occurred to intussusception (ICD (ninth revision) code 560.0).

Symptoms and signs - The presenting clinical features of the patients are shown in table III. Vomiting was the commonest symptom and was noted to be bilious in six patients, but the content of the vomitus was not 
recorded in 18 cases. Only five children had a palpable abdominal mass, and pallor was specifically noted in only two. The classical triad of abdominal pain, vomiting, and bleeding was present in only six patients.

\section{FACTORS CONTRIBUTING TO DEATH}

Potentially avoidable factors were considered to be present in 20 children, 17 of whom had ileocolic intussusception (table IV).

Delayed referral was considered to have occurred when a general practitioner had been consulted and hospital referral had not been made after two visits or within 48 hours of the onset of symptoms. Delayed diagnosis indicated a failure to diagnose intussusception within 24 hours of admission to hospital. Fluid replacement was judged to be inadequate if only daily maintenance crystalloid requirements or less (in the absence of colloid) were given to children having surgery; all such patients were clinically hypovolaemic. Septicaemia was considered a potentially avoidable factor in patients with positive blood cultures and disseminated intravascular coagulation ${ }^{8}$ or in those having surgery without antibiotic cover (in whom infarcted bowel was present in three of the four). Hyperpyrexia was defined as a central temperature of $>40.5^{\circ} \mathrm{C}$. Severe hypoglycaemia was evidenced by repeated blood glucose concentrations below $1-2 \mathrm{mmol} / \mathrm{l}$

Hydrostatic reduction by barium enema was attempted in four patients with ileocolic intussusception but failed in two, who had surgery. In the other two patients, who had ileoileocolic intussusception, barium was seen to fill the terminal ileum and the reduction considered complete but the reduction was either inadequate or the intussusception recurred. Both children remained unwell with a persistent tachycardia, fever, and abdominal signs. Vomiting and

TABLE II - Time and place of death from intussusception $(n=33)$

\begin{tabular}{lc}
\hline Time and place & $\begin{array}{c}\text { No (cumulative \%) } \\
\text { of cases }\end{array}$ \\
\hline At home & $5(15)$ \\
Day of admission (no surgery) & $12(52)$ \\
After day of admission (no surgery) & $1(55)$ \\
Within 24 hours of surgery & $9(82)$ \\
Within 2-4 days of surgery & $5(97)$ \\
On 22nd day after surgery & $1(100)$
\end{tabular}

TABLE III - Symptoms and signs related to anatomy of intussusception. (Percentages are given in parentheses)

\begin{tabular}{lccc}
\hline $\begin{array}{l}\text { Presenting clinical } \\
\text { features }\end{array}$ & $\begin{array}{c}\text { Colonic } \\
\text { intussusceptum } \\
(\mathbf{n}=22)\end{array}$ & $\begin{array}{c}\text { Small bowel } \\
\text { intussusceptum } \\
(\mathbf{n}=11)\end{array}$ & $\begin{array}{c}\text { Total } \\
(\mathbf{n}=33)\end{array}$ \\
\hline Vomiting & $22(100)$ & $9(82)$ & $31(94)$ \\
Abdominal pain & $11(50)$ & $5(45)$ & $16(48)$ \\
Rectal bleeding & $13(59)$ & 0 & $13(39)$ \\
Abdominal mass & $4(18)$ & $1(9)$ & $5(15)$ \\
Severe lethargy & $7(32)$ & $3(27)$ & $10(30)$ \\
Fever $>38^{\circ} \mathrm{C}$ & $7(32)$ & $3(27)$ & $10(30)$ \\
Diarrhoea & $2(9)$ & $1(9)$ & $3(9)$ \\
\hline
\end{tabular}

TABLE IV-Potentially avoidable factors contributing to death from intussusception

\begin{tabular}{lc}
\hline Factor & $\mathrm{No}^{\star}(\mathbf{n}=33)$ \\
\hline Delayed referral & 6 \\
Delayed diagnosis & 6 \\
Inadequate fluid resuscitation & 7 \\
Sepsis & 5 \\
Absent/inadequate nasogastric decompression & 2 \\
Failure to recognise incomplete/recurrent intussusception & 2 \\
Excessive delay between resuscitation and surgery & 1 \\
Operative complications & 5 \\
Postoperative hyperpyrexia & 2 \\
Severe postoperative hypoglycaemia & 2 \\
\hline Total & $20(61 \%)$ \\
\hline \multirow{2}{*}{ Multiple factors were present in 10 children. }
\end{tabular}

TABLE $\mathrm{v}-$ Operative complications contributing to death from intussusception

\begin{tabular}{lll}
$\begin{array}{l}\text { Case } \\
\text { No }\end{array}$ & Operative findings & Outcome \\
\hline 1 & Difficult reduction & $\begin{array}{l}\text { Infarcted ileum and perforated transverse } \\
\text { colon(second laparotomy) }\end{array}$ \\
2 & $\begin{array}{l}\text { Gangrenous caecum } \\
\text { Difficult reduction }\end{array}$ & $\begin{array}{l}\text { Considered too ill to resect } \\
\text { Gangrenous caecum and perforated } \\
\text { transverse colon (second laparotomy) }\end{array}$ \\
4 & Simple reduction & $\begin{array}{c}\text { Distal ileal perforation (necropsy) } \\
\text { Ileal infarction (necropsy) }\end{array}$ \\
5 & Simple reduction & . \\
\hline
\end{tabular}

aspiration led to respiratory arrest six hours later in one child, and a gangrenous ileoileal intussusception was subsequently resected. The other patient underwent laparotomy 12 hours later, when a Meckel's diverticulum associated with a viable intussusception was resected, but septicaemia and renal failure resulted in further deterioration.

Fifteen children had laparotomy, and surgical complications occurred in five (table V). Only one of these patients was under the care of a specialist paediatric surgeon. These complications resulted from failure to recognise and resect small or large bowel (intussus ceptum or intussuscipiens) of dubious viability. Ischaemic intestinal perforation or multisystem failure or both, ensued.

Of the 13 patients in whom no avoidable factors were identified, three died at home or on arrival at hospital without prior medical consultation. There were two deaths in which short ileoileal intussusceptions may have been agonal events complicating bronchiolitis and sudden infant death respectively. ${ }^{9}$ Within this group of 13 deaths were nine of the 11 children with isolated small bowel intussusception, who tended to have atypical histories characterised by a short duration (less than 24 hours in six cases) and profuse vomiting with or without abdominal pain but without rectal bleeding or a palpable abdominal mass. Aspiration pneumonitis was recorded at necropsy in seven cases.

Other factors - Most of the children had been fit and healthy before the onset of their intussusception, but additional clinical problems had been present in five, only two of whom had avoidable factors: congenital hypogammaglobulinaemia and bronchiectasis ${ }^{10}$; structural cerebral abnormalities with mental retardation in two patients; recurrent supraventricular tachycardia; and Robert's syndrome (cleft lip and palate, tetraphocomelia, and growth deficiency). ${ }^{11}$

\section{MORTALITY AND HOSPITAL DEATH RATES}

The number of deaths from intussusception in England and Wales halved between 1978-83 and 1984 9. ${ }^{6}$ Estimations based on mortality and population statistics indicate a decrease in the death rate from intussusception in children under 1 year from $14 \cdot 3 /$ million in $1978-83$ to $5 \cdot 8$ /million in $1984-9$. Other data show no evidence of a decrease in the hospital discharge rate of children with a diagnosis of intussusception. ${ }^{3-5}$ Thus the fall in death rates was likely to reflect improved medical care.

\section{Discussion}

This group of patients who died of intussusception differed from reported series of childhood intussusception in two main respects. Firstly, small bowel intussusception was present in one third of the cases but normally accounts for less than $10 \%$ of all childhood intussusceptions. ${ }^{12-14}$ As confirmed in this study, small bowel intussusception does not tend to produce the classic symptoms and signs of intussusception, and diagnosis is often delayed until a laparotomy is performed for intestinal obstruction. Secondly, only half of the children with ileocolic intussusception had a 
history of abdominal colic, and in only one fifth was there a palpable abdominal mass. This contrasts with the findings in most studies of childhood intussusception, in which $80-90 \%$ of patients present with evidence of abdominal pain and at least half have a palpable abdominal mass. ${ }^{1+17}$ The infrequency of a palpable mass in our series may reflect the fact that many children were admitted with advanced intestinal obstruction and associated abdominal distension.

Most children with intussusception present to hospital within 48 hours of the onset of symptoms. ${ }^{18}$ Delayed referral or diagnosis was present in over one third of deaths in this series and undoubtedly contributes to morbidity from intestinal infarction and bowel resection in survivors. ${ }^{12} 18$ General practitioners may find difficulties in diagnosis given both the infrequency with which they encounter intussusception and the frequency with which intussusception fails to present in the classic textbook manner. Although this is particularly true of isolated small bowel intussusception, ${ }^{20}$ it is noteworthy that diagnostic difficulties were encountered in half the cases analysed in a recent large study of all childhood intussusceptions from a children's hospital. ${ }^{18}$

\section{DIAGNOSTIC POINTS}

Several diagnostic points must be emphasised. Although intussusception is reasonably regarded as a condition of infancy, it does occur in older children. Between $10 \%$ and $30 \%$ of intussusceptions are recorded in children over 2 years of age, ${ }^{121315}$ and five of the deaths in this study were in children over 8 years old. Bilious vomiting as a sign of intestinal obstruction seems to be underestimated; it was reported in six of the 15 patients in whom a specific inquiry was made but its relevance was rarely appreciated. In most of the deaths the nature of the vomitus was not recorded.

Between $13 \%$ and $20 \%$ of children with intussusception have no signs of abdominal colic or discomfort, the so called painless intussusception. ${ }^{15{ }^{1721}}$ Ein $e t$ al found that these infants take twice as long to reach hospital and have a significantly greater incidence of irreducible intussusception compared with those presenting with abdominal pain. ${ }^{21}$ The degree and type of rectal bleeding in intussusception is variable and may cause confusion with infective gastroenteritis. ${ }^{18}$ Children with established intussusception may appear deceptively well, ${ }^{20}$ but intussusception must also be considered in the differential diagnosis of the listless or collapsed infant with minimal abdominal signs. ${ }^{120} 22$ Plain radiography, abdominal ultrasound scanning, and contrast enema studies by a radiologist with paediatric expertise are relatively non-invasive methods of confirming most intussusceptions. ${ }^{12324}$

It is disappointing to discover that inadequate fluid replacement contributed to one fifth of the deaths, particularly since this has been well documented as a factor in mortality from appendicitis. ${ }^{78}$ Often there is a continuing need for large volumes of fluid during and after surgery, and adequate monitoring of the circulation by peripheral skin temperature probes and urine output is vital. During the transfusion of large volumes of colloid blood glucose concentrations must be monitored.

It is now generally accepted that most cases of intussusception can be successfully managed without surgery by using hydrostatic or pneumatic reduction techniques. ${ }^{1+181925}$ However, if symptoms and signs are not rapidly relieved after an apparently successful radiological reduction residual or recurrent intussusception must be suspected. Pitfalls in the assessment of radiological reduction are well recognised, and free reflux of contrast into the terminal ileum does not necessarily exclude the possibility of a residual ileocolic intussusception ${ }^{2627}$ or an ileoileal component. ${ }^{25}$

Finally, in the metabolically unstable patient with a prolonged postoperative ileus the possibility of perforated or ischaemic bowel must not be overlooked. Refractory postoperative hypoglycaemia and acidosis may indicate the presence of surgical complications.

Improvements in the management of childhood intussusception are likely to be gained from a wider awareness of its various presentations, prompt and aggressive resuscitation, and expeditious treatment in a centre with combined paediatric radiological, anaesthetic, and surgical expertise.

We thank the consultants, coroners, and medical records officers who provided the information which made this study possible.

1 Ravitch MM. Intussusception. In: Welch KJ, Randolph JG, Ravitch MM O'Neill JA, Rowe MI, eds. Pediatric surgery. 4th ed. Chicago: Year Book Medical Publishers 1986:868-82.

2 Steyn J, Kyle J. Epidemiology of acute intussusception. BMF 1961;i:1730-2.

Department of Health and Social Security. Hospital inpatient enquiry. London HMSO, 1978-85.

4 Department of Health and Social Security. Hospital activity analysis. London: HMSO, 1987-8.

5 Welsh Office. Hospital activity analysis. Cardiff: Welsh Office, 1982-8.

6 Office of Population Censuses and Surveys. Mortality statistics-childhood. London: HMSO, 1978-88.

Pledger HG, Buchan R. Deaths in children with acute appendicitis. $B M \mathcal{F}$ 1969;iv:466-70.

8 Pledger HG, Fahy LT, van Mourik GA, Bush GH. Deaths in children with a diagnosis of acute appendicitis in England and Wales 1980-4. BMF 1987;295:1233-5.

9 Nixon JR. Multiple "agonal" intussusception of the small bowel. Fournal of the Irish Medical Association 1974;67:134-5.

10 Campling EA, Devlin HB, Lunn JN. Report of the national confidential enquiry into perioperative deaths, 1989. London: Royal College of Surgeons of England, 1990.

1 Goodman RM, Gorlin RJ. The malformed infant and child. Oxford: Oxford University Press, 1983.

12 Dennison WM, Shaker $M$. Intussusception in infancy and childhood. Brf Surg 1970;57:679-84.

13 Ein SH, Stephens CA. Intussusception: 354 cases in 10 years. $\mathcal{F}$ Pediatr Surg 1971;6:16-27.

14 Bruce J, Huh YS, Cooney DR, Karp MP, Allen JE, Jewett TC. Intussuscep tion: evolution of current management. I Pediatr Gastroenterol Nutr 1987;6:663-74.

15 Hutchison IF, Olayiwola B, Young DG. Intussusception in infancy and childhood. Br f Surg 1980;67:209-12.

16 Beasley SW Auldist AW, Stokes KB. Recurrent intussusception: barium or surgery? Aust N Z F Surg 1987;57:11-4.

17 Sparnon AL, Little KET, Morris LL. Intussusception in childhood: a review of 139 cases. Aust N Z F Surg 1984;54:353-6.

18 Beasley SW, Auldist AW, Stokes KB. The diagnostically difficult intussusception: its characteristics and consequences. Pediatric Surgery International $1988 ; 3: 135-8$.

19 West KW, Stephens B, Vane DW, Grosfeld JL. Intussusception: curren management in infants and children. Surgery 1987;102:704-10.

20 Morrison B, Court D. Acute intussusception in childhood. BMF 1948; 776-80.

21 Ein SH, Stephens CA, Minor A. The painless intussusception. 7 Pediatr Surg 1976;11:563-4.

22 Hickey RW, Sodhi SK, Johnson WR. Two children with lethargy and intussusception. Ann Emerg Med 1990;19:390-2.

23 Eklof $\mathrm{O}$, Hartelius $\mathrm{H}$. Reliability of the abdominal plain film diagnosis in pediatric patients with suspected intussusception. Pediatr Radiol 1980;9: pediatric pat

24 Pracros JP, Tran-Minh VA, Wright C. Ultrasound in diagnosis of intussusception. Lancet 1985;ii:733-4.

25 Palder SB, Ein SH, Stringer DA, Alton D. Intussusception: barium or air? 7 Pediatr Surg 1991;26:271-5.

26 Fitch SJ, Magill HL, Benator RM, Parvey LS, Hixson SD. Pseudoreductio of intussusception: is ileal reflux the end point? Gastrointest Radiol 1985;10:181-3.

27 Hedlund GL, Johnson JF, Strife JL. Ileocolic intussusception: extensive reflux of air preceding pneumatic reduction. Radiology 1990;174:187-9.

Accepled 20 December 1991

\section{Correction}

Community surveillance of complications after hernia surgery

An authors' error occurred in this paper by Ian S Bailey and colleagues (22 February, p 469). In the second paragraph of the results section the wound grades should be IV and V and not III and IV as printed. 